\title{
Volatility Spillover from the Fear Index to Developed and Emerging Markets
}

\author{
Ihsan U. Badshah ${ }^{*}$
}

ABSTRACT: This paper examines the volatility linkages among the fear index (VIX), the developed stock market volatility index (VXEFA), and the emerging stock market volatility index (VXEEM). We find significant cross-market dependencies in first as well as in second moments of volatilities. The fear index has leading role and has information content for both developed and emerging markets. A volatility shock to the fear index spillovers to the developed and emerging markets and able to explain about $57.07 \%$ and $63.77 \%$ of their unexpected volatility shocks, respectively; the effect of the shock persists for about 7 days. We further analyse the cross-market dependencies in second moments of volatilities and find that the correlations among the markets are time-varying not constant. Both developed and emerging markets are highly correlated with the fear index, and the fear index drives the correlation dynamics of the emerging markets. The dynamic correlations increase in turbulent periods and decreases in tranquil periods. Our findings have important implications for the international portfolio diversification, hedging and risk management.

KEY WORDS: Emerging markets, implied volatility spillover, VIX, VXEEM, VXEFA

\footnotetext{
* Address: Department of Finance, AUT Business School, Auckland University of Technology, Private Bag 92006, Auckland 1142, NEW ZEALAND. E-mail: ibadshah@aut.ac.nz. Tel: +64-9 9219999 extn: 5394. Fax: +6499219940.
} 


\section{Introduction}

The degree of world stock market integration has been increasing over the past two decades due to economic integration through trade and financial linkages which has led to an increase in equity returns correlations among stock markets across the globe (see Bekaert and Harvey 2014). It is known that the high degree of stock market correlation evaporates the benefits of diversification available in the investment opportunity set to international investors. However, empirical evidence suggests that many of the emerging markets are not yet completely integrated into the global stock markets rather still segmented; moreover, they find that emerging market equities have high returns, high risks, and lower correlations with the developed market equities, usually these characteristics attract international investors (see Bekaert et al., 2011; Bekaert and Harvey, 2014). Emerging markets are economically linked with the US and other developed markets through trade and investments thus the emerging market volatilities (risks) may be dependent on the US and other developed markets volatilities (risks).

We know that market volatility vary much more than market returns so inter-market volatilities should reveal the dynamics of market integration and spillovers effect much better than market returns (see Peng and Ng, 2012). We rely on the forward-looking volatility indices the VIX, VXEFA, and VXEEM reflecting the volatilities of the US, emerging and other developed stock markets (excluding the US), respectively. The Chicago Board of Options Exchange (CBOE) has launched, VXEEM, for the for emerging stock markets on March 16,2011, and on June 27, 2013, VXEFA, for developed stock markets the history of the latter goes back to January 2, 2008. VXEEM is calculated from options traded on the underlying the iShare MSCI Emerging Markets ETF (which provides exposure to 26 emerging stock stock) whereas VXEFA is calculated from options traded on the underlying iShares MSCI EAFE ETF (which provides exposure to 24 developed stock markets i.e. developed Europe, Australasia 
and Far eastern countries). We use the above forward-looking volatility indices rather than historical market volatilities because volatility index such as VIX is now widely considered investors fear gauge because it is implied from a cross-section of put and call options on the S\&P 500 stock market index. It is known that the stock index puts are usually used by investors for hedging their underlying stock portfolios. Therefore, volatility index better reflects investor's expectation about the future stock market volatility than any other volatility measure (see Blair et al.,2001). It also reflects overall investors risk aversion in the stock market which is fundamental for portfolios (Bollerslev et al., 2009). Other main advantage of using volatility indices is that a variety of volatility derivatives are traded on the $\mathrm{CBOE}$ on these volatility indices such as options and futures; therefore, these volatiyt derivatives facilitate to hedging and diversification of risks associated with the underlying international equity portfolios.

Thus, international investors would like to know the answers of the following questions. ${ }^{1}$ How closely these markets are linked with respect to volatilities. ${ }^{2}$ who causes who? Can unexpected shock to the US stock market volatility predict the unexpected risk of emerging market volatility or developed market volatility and vice versa? And for how many days the effect of an unexpected shock on the volatility will persist? How they are linked in terms of second moments of volatilities? Are their correlations time-varying or static? And dynamic correlations behave differently during turbulent and tranquil periods? It is important that international investor understand the cross-volatility linkages and correlation dynamics so they could optimally decide on their portfolios and to take adequate decisions to manage their risks.

Volatility literature provide empirical evidence on the market integration and volatility spillover effects across the developed markets such as the US and European markets (Nikkinen and Sahlström 2004; Skiadopoulos 2004; Nikkinen et al. 2006; Äjiö 2008; Jiang et al. 2012; Peng and Ng, 2012;Kenourgios, 2014). Äijö(2008) investigates volatility linkages between European volatility indices (VDAX, VSMI and VSTOXX). He finds that the volatility indices 
are highly correlated and implied volatility indices vary over time, the VDAX being the dominant source of volatility information. VDAX can explain the variance of the forecast errors of the VSTOXX and VSMI about $65 \%$ and 35\%, respectively. Nikkinen and Sahlström (2004) study the degree of market integration between the US, UK, German and Finnish stock markets using implied volatility indices. Similarly, they find a high degree of integration among these markets: while the US market is the leading source of information transmitting to other markets generally, in the European context the German market leads other European markets. Jiang et al. (2012) investigates implied volatility linkages between the US and many European stock markets. They find significant spillovers between the US and Europe and spillovers within Europe. Moreover, they provide evidence of volatility contagion across markets during the global financial crises of 2008. Peng and $\mathrm{Ng}$ (2012) study the inter-dependence among five major US, European and Japanese volatility indices (VIX, VXN,VDAX, VFTSE, and VXJ) and show that they are highly correlated and the dependence between volatility indices is effected by financial shocks reveals information much faster than the underlying stock market indices. A recent study by Kenourgios (2014) study the volatility contagion across US and European volatility indices (VIX, VCAC, VDAX, VFTSE, VSMI) using the Asymmetric dynamic conditional correlation GARCH model of Cappiello et al. (2006). He finds volatility indices highly correlated, and their correlations are time-varying not constant, and their correlations considerably increases during the crises periods.

Our study builds on the above literature but differs from the existing research in two respects. We study volatility spillovers across the US stock market, the emerging stock market, and the rest of the developed stock market. To our knowledge, our study is the first to investigate the implied volatility spillovers among the US, the developed and the emerging market using data on the newly introduced CBOE volatility indices. Second, we use multivariate GARCH model of Cappiello et al. (2006) to analyse the dependencies and 
spillovers effects in second moments of volatilities across markets.

Our main findings are that there is considerable volatility spillover from the fear index (the VIX) to the developed and emerging market volatility indices. The dependencies and spillovers are found by analysing both moments of volatilities. The fear index has a leading role and has predictability for emerging and developed market volatilities; however, we also find emerging markets informative for developed markets but not vice versa. The effect of a unit VIX risk shock has persistent effects (for about 7 days ahead) on emerging and developed market volatilities. Moreover, the fear index risk shock spillovers to developed and emerging markets risks about $57.07 \%$, and $63.77 \%$, respectively.

We also analyze the interdependencies in second moments of volatilities (i.e. voaltilties of volatilities) by using ADCC-GARCH model. The results shows voaltilty indices are highly persistent and present asymetries in volatility to negative and positive shocks. Second, the correlations between these markets are time-vayring therefore we reject the assumpiton of contant correlations. Third, the fear index is dynamically correlated with the developed and emering markets and particularly it drives persitently the correlations of emerging market volatilies; however, the dynmic correlation between the developed and emerging market is volatile and less persistent. Finally, time-vayring correlations increases in turnbulent periods and decrease in tranquil periods.

This paper is organized as follows. In Section 2, we discuss the data. In Section 3, we study the cross-market linkages in first moments of volatilities. In Section 4, we study crossmarket linkages in second moments of volatilities. Lastly, section 5 concludes.

\section{Data}

We obtain daily data on the VIX, VXEFA, and VXEEM from the Chicago Board of Option Exchange website for the sample period March 16, 2011 to October 30, 2015. The CBOE 
introduced VIX in September 2003, which is computed from the bid and ask prices of the crosssection of S\&P 500 options. ${ }^{3}$ The CBOE introduced, VXEFA for developed stock markets excluding United States on June 27, 2013, ${ }^{4}$ and on March 16, 2011, VXEEM for the emerging stock markets, the history of the former goes back to January $2,2008 .{ }^{4}$ VXEFA is computed from options traded on the underlying iShares MSCI EAFE ETF (which provides exposure to 24 developed stock markets i.e. developed Europe, Australasia and Far eastern countries), whereas VXEEM is computed from options traded on the underlying the iShare MSCI Emerging Markets ETF (which provides exposure to 26 emerging stock markets). Using similar model free methodology as VIX, CBOE computes VXEFA and VXEEM from the bid and ask prices of the cross-section of iShare MSCI EAFE ETF options and iShare MSCI Emerging Markets ETF options, respectively. It is important to note that options on the underlying S\&P 500 index, MSCI developed market ETF and emerging market ETF are traded at the same trading hours on the CBOE platform. Thus our data on the volatility indices are not subject to trading time differences.

Figure 1 shows a time series plot of the daily closing levels (\%) of the three implied volatility indices from March 16, 2011 to October 30, 2015. Among the three volatility indices, the VXEEM presents the highest volatility level throughout our sample period, whereas the VIX shows the lowest volatility level. In later part of 2011, there are considerably high volatility levels which is due to the European debt crises. However, from 2012 onwards until the second quarter of 2015 , volatility levels are relatively stable. On August $24^{\text {th }}$, the Chinses stock market plunge about $8.5 \%$ in value (called the Chinese Black-Monday), triggering worldwide stock market fall, and a spike of 55\% can be seen in the VXEEM on that day, the levels of VIX hit $36 \%$ and VXEFA $41 \%$. The high volatility levels continue until the end of September, 2015.

Table 1 reports summary statistics for the VIX, VXEFA, and VXEEM. First three 
columns of Table 1 present summary statistics for the volatility levels. As can be seen, on average VXEEM has the highest level followed by VXEFA, and VIX. During the sample period, the maximum level the VXEEM has ever reached is $64 \%$, the VXEFA with about $59 \%$ and the VIX about $48 \%$. All three volatility indices are positively skewed and present excess kurtosis. First order autocorrelations for all three volatility indices are reported in row 10, which show all three volatility indices are highly persistent. The Augmented Dicky Fuller (ADF) tests on levels data, we can easily reject the null hypothesis of unit root for the VIX, VXEFA, and VXEEM.

Last three columns of Table 1 provide summary statistics for log changes in the VIX, VXEFA, and VXEEM, respectively. Mean values of log volatility changes are about zero; however, there are dispersions on a daily basis as can be seen from the maximum, minimum, and standard deviation. All three volatility indices are positively skewed, which suggest that big positive changes in the volatility indices occur more frequently than big negative changes. All three indices show excess kurtosis. The excess kurtosis in the volatility indices suggest that big volatility changes occur more frequent in comparison to the normally distributed volatility changes. Based on the ADF tests on the log changes data, we can reject the null hypothesis of unit root at $1 \%$ level.

\section{Cross-market Linkages in First Moments of Volatilities}

\section{VAR Framework}

We investigate the dynamic cross-market linkages in first moments of VIX, VXEFA, and VXEEM changes in the Vector Autoregressive (VAR) framework. The VAR model can capture the dynamic impact of random innovations on a system of variables. It treats each endogenous variable in a system as a function of the lagged value of all endogenous variables in a dynamic simultaneous equations system. The VAR model for log changes in the VIX, 
VXEFA, and VXEEM can be specified as follows:

$$
\Delta V I_{t}=\alpha+\sum_{i=1}^{L} \Phi_{i} \Delta V I_{t-i}+u_{t}
$$

Where $\Delta V I_{t}=\left(\Delta V I X_{t}, \Delta V X E F A_{t}, \Delta V X E E M_{t}\right)^{\prime}$ is an $\mathrm{mx} 1$ vector of endogenous variables representing the daily $\log$ changes in the volatility indices; $\left[\Phi_{i}, i=1,2,3, \cdots, L\right]$ is an $m \times m$ matrix of coefficients; and $u_{t}$ is an $m \times 1$ vector of innovations which can be contemporaneously correlated; however, uncorrelated with its own lagged values and with other variables. The Schwarz Information Criterion (SIC) is used to select appropriate lag structure for the VAR model. SIC suggests 2 lags, thus we select VAR (2) as our specification for further analysis. The VAR model is estimated by ordinary least squares (OLS) method.

In Table 2, we provide coefficient estimates for the VAR(2) model and t-statistics in squared brackets. For $\Delta \mathrm{VIX}_{\mathrm{t}}$, we receive a negative and significant coefficient estimate on $\Delta \mathrm{VIX}_{\mathrm{t}-1}$ implying that there is a negative autocorrelation in $\Delta \mathrm{VIX}$, this shows mean-reversion property in the VIX level. However, the coefficient estimate on $\Delta \mathrm{VIX}_{\mathrm{t}-2}$ is statistically insignificant. While the coefficient estimate on the $\triangle V_{X E F A}-1$ for $\Delta \mathrm{VIX}_{\mathrm{t}}$ is found to be negative and insignificant whereas the coefficient estimate on $\triangle \mathrm{VXEEM}_{\mathrm{t}-1}$ is positive but similarly found to be insignificant, suggesting that developed and emerging markets volatilities do not effect significantly the volatility of the US stock market.

For $\triangle \mathrm{VXEFA}$, we receive a negative and significant coefficient on $\triangle \mathrm{VXEFAt}$-1 and $\triangle$ VXEFAt-2 implying that there is a negative autocorrelation in $\triangle$ VXEFA, this also indicates mean-reversion property in the VXEFA. We find positive and statistically significant coefficients on $\Delta \mathrm{VIX}_{\mathrm{t}-1}$, and $\Delta \mathrm{VIX}_{\mathrm{t}-2}$ at $1 \%$ level, suggesting that the VIX can predict at a large extent the volatility of developed stock markets. On the other hand, we receive positive and significant coefficients on $\triangle \mathrm{VXEEM}_{\mathrm{t}-1}, \triangle \mathrm{VXEEM}_{\mathrm{t}-2}$ at $1 \%$ and $5 \%$ level respectively for $\triangle \mathrm{VXEFAt}$, suggesting that the emerging market volatility contain significant volatility 
information content for the VXEFA.

Finally, for $\triangle \mathrm{VXEEM} \mathrm{t}$, we find negative and significant coefficients on $\triangle \mathrm{VXEEMt}-1$ and on its lag 2, confirming mean-reversion in the VXEEM. We find positive and significant coefficients on $\Delta \mathrm{VIX}_{\mathrm{t}-1}$, and $\Delta \mathrm{VIX}_{\mathrm{t}-2}$. Which suggest shocks to the VIX up to lagged 2 days in the VIX have information content to predict unexpected changes in the current volatility of the emerging markets. On the other hand, we receive negative coefficients on $\triangle V_{X E F A}$, and $\triangle \mathrm{VXEFAt}$-2 but the former being insignificant and the latter marginally significant, suggesting that immediate volatility shock in the developed market does not carry predictive information for the emerging market volatility; however, emerging markets investors react at slower pace with anticipation that the unexpected shock in developed markets would not lead to increases in the volatility. Overall, the results from the VAR (2) specification suggest that the unexpected volatility shock generated in the US market leads to significant increases in both emerging market and developed market volatilities. The unexpected volatility shocks generated in the emerging and developed market do not affect the volatility of the US market; however, the emerging market shock significantly increases the volatilities of developed markets. This US volatility effect on the emerging markets volatilities reflects the underlying economic channel. For instance, emerging markets' economies are heavily dependent on exports to the US and investments of US multinationals; therefore, emerging market investors would perceive any risk to the US equity market as a shock to the demand of their exports and a possible decline in investments. Furthermore, the results are consistent with the findings of Rizova (2013) who finds that emerging stock markets react gradually to the unexpected shocks of their trading partner countries therefore we see a lagged response from the emerging markets investors. Similarly, developed markets excluding the US such as Japan and Germany etc. their economies are heavily exports dependent to the US and emerging markets so we see volatility spillover effects on the developed market volatilities. 
Finally, the last row of Table 2 provides $\mathrm{R}^{2}$ values for $\triangle \mathrm{VIX}_{\mathrm{t}}, \triangle \mathrm{VXEFA}$, and $\triangle$ VXEEMt, which are very low, $0.73 \%, 5.47 \%$, and $1.57 \%$, respectively. Which suggest that the volatility dynamics of developed markets are relatively more predictable in comparison to the US and emerging market volatilities.

Table 3 provides results for pairwise Granger (1969) causality tests, which establishes lead-lag relationships between these markets. The results further confirm our findings of Table 2 that the fear index significantly Granger causes developed and emerging market volatilities. Surprisingly, developed markets do not causes the US and emerging market volatilities but emerging market significantly causes developed market volatilities.

\section{Impulse Responses}

Information on the sign and persistence of a shock in the VAR system can be gleaned from impulse response functions. For example, how long the effect of a unit shock to the volatility of one market would have on the volatility of another market. An impulse response function measures the responses of volatility in a VAR system to a unit shock in each volatility index. We use the generalized impulse response function (GIRF) of Pesaran and Shin (1998), as it does not require orthogonalization of shocks and invariant to the reordering of the volatility variables in the VAR System.

Figure 2 provides accumulated generalized impulse responses of $\triangle$ VIX, $\triangle$ VXEFA, and $\triangle \mathrm{VXEEM}$ for 30 steps ahead. Panel A depicts the accumulated impulse responses of $\Delta \mathrm{VIX}$ to a unit shock in the innovations of the VIX, VXEFA, and VXEEM. The contemporaneous GIRFs of the VIX are $0.073,0.057$, and 0.059 units to a unit shock in the VIX, VXEFA, and VXEEM, respectively. For the next few days ahead the impact of its own shock on the VIX decreases and a similar pattern can be observed to the shocks of VXEFA, and VXEEM. The GIRF of VIX return to a more stable level after about 5 days at about $0.068,0.052,0.055$ for a shock in the VIX, VXEFA, and VXEEM, respectively. 
Panel B shows the accumulated generalized impulse responses of $\triangle$ VXEFA to a unit shock in the VIX, VXEFA and VXEEM. The contemporaneous repossess of the VXEFA to a unit shock in each volatility index are $0.054,0.070$, and 0.053 units, respectively. The effect of a unit shock on the VXEFA decreases after a few days and return to a more steady level after 6 days and settle down at about $0.056,0.062$, and 0.054 , respectively.

Panel $\mathrm{C}$ shows the generalized accumulated impulse responses of $\triangle \mathrm{VXEEM}$ to a unit shock in the VIX, VXEFA VXEEM. A unit shock in each volatility index leads to contemporaneous responses in the VXEEM of $0.050,0.046$, and 0.062 units, respectively. The effect of a unit own shock stays for a while and revert to a steady level after about 10 days. Somehow similar responses can be seen to a unit shock in the VIX and VXEFA. Nonetheless, the effect of a unit shock in each volatility index reaches to steady level after 7 periods and settle down at about $0.052,0.046$, and 0.059 , respectively.

In sum the GIRF results suggest that the effect of a shock to each volatility index have long-run implications for the volatilities of each studied market, thus persistent. However, if we compare the effect of each shock on each volatility index then the shock in the fear index has the strongest effect on both developed and emerging markets, the effect persists for about 7 days ahead. Which is consistent with the gradual diffusion of volatility information.

\section{Variance Decomposition}

While impulse response functions capture the effects of a shock to the volatility of one market to the other market volatility in a dynamic VAR system, whereas variance decomposition or forecast error decomposition allows us to split the forecast error variance into slices attributable to the various system shocks. For example, what percentage of the 1-step ahead error variance in predicting volatility index $i$ is due to shocks in the other volatility indices (see Mills and Markellos, 2008; Diebold and Yilmaz, 2009).

Figure 3 depicts the variance decompositions for VIX, VXEFA, and VXEEM for 30 
steps ahead. There are three panels in Figure 3; the y-axis shows the percentage of error variances in forecasting a volatility index $i$ due to shocks in other volatility indices. While the $\mathrm{x}$-axis of each panel shows the number of steps ahead error variance forecast. Panel A plots the variance decomposition of the fear index (the $\Delta$ VIX). As can be seen, the fear index explains all of its own 1-step ahead forecast error variance, and on average $99.76 \%$ of its 30 -day ahead forecast error variance. However, the other volatility indices contribute to the forecast error variance of the VIX marginally, on average about $0.12 \%$ each.

The variance decomposition of the developed market volatility (VXEFA) is plotted in Panel B of Figure 3. VXEFA can forecast $39.92 \%$ of its own 1-day ahead error variance and on average about $42.14 \%$ for 30 -day ahead forecast error variance. However, VIX seems to dominate here as it explains about $60.08 \%$ of the error variance of VXEFA 1 -step ahead and on average about $57.07 \%$ for 30 -step ahead. While the emerging market volatility index contributes marginally to the total predictability of VXEFA.

Panel $\mathrm{C}$ of Figure 3 shows the variance decomposition of the emerging market volatility index (VXEEM) for 30-step ahead. As can be seen, VXEEM can forecast its own 1-step ahead error variance about $31.42 \%$, and on average about similar explanation for 30 -step ahead. On the other hand, VIX seems to dominate in 1-step ahead error variance forecasting for the emerging market volatility (VXEEM) as well, as VIX can predict up to $64.50 \%$ of the error variance for VXEEM, and on average about $63.77 \%$ for 30 -step ahead. However, the forecasting ability of the developed stock market volatility is found quite low for the VXEEM.

The main conclusion drawn from the Variance decomposition results is that the fear index clearly drives the volatilities of both developed and emerging stock markets. As a shock to the fear index spillovers to both developed and emerging market volatilities and can explain the variance of volatility shocks to developed and emerging market volatilities on average about $57.07 \%$ and $63.77 \%$, respectively. However, the spillovers from the other volatility 
indices to the fear index are negligible. One important observation from the spillover results can be seen that VIX influences emerging market more than the developed market. These results further verify our earlier results of VAR, and impulse response analysis.

\section{Cross-market Linkages in Second Moments of Volatilities}

\section{The Multivariate GARCH-ADCC Model}

We further investigate whether the US market, developed markets and emerging markets are dynamically correlated in second moments of volatilities. How strongly they are correlated, are their correlations time-varying or static? Are their correlations asymmetric? Answers to these questions are important for international investors. We employ the asymmetric dynamic conditional correlation GARCH model (ADCC-GARCH) of Cappiello et al. (2006). It is a generalization of the DCC-GARCH model of Engle (2002) to account for the conditional asymmetries in correlation. ADCC-GARCH model allows correlations to vary over time, while it involves two-step procedure to isolate the dynamic conditional correlation process. In step 1, a univariate asymmetric GARCH model is fitted for each volatility residuals series (residuals are received from VAR (2) specification) and use the time varying estimated standard deviation to obtain standardized residuals series for each volatility index. In step 2 , the standardized residuals (standardized volatility shocks) are used to estimate the time-varying dynamic conditional correlations. Let $u_{t}$ denotes a $n \times 1$ vector of volatility residuals at time $t$, which is assumed to be conditional normally distributed with mean zero and covariance matrix $V_{t}$ as

$$
u_{t} \mid \Psi_{t-1} \sim N\left(0, H_{t}\right)
$$

Where $\Psi_{t-1}$ is the information set available at time $t-1$, and the conditional covariance matrix $V_{t}$ is as

$$
V_{t}=D_{t} C_{t} D_{t}
$$


where $D_{t}$ is the diagonal matrix of time-varying standard deviations obtained from the fitted univariate asymmetric GJR-GARCH models at step 1, whereas $C_{t}$ is the time-varying conditional correlation matrix given by

$$
C_{t}=\operatorname{diag}\left(Q_{t}\right)^{-1 / 2} Q_{t} \operatorname{diag}\left(Q_{t}\right)^{-1 / 2},
$$

Where $\operatorname{diag}\left(Q_{t}\right)$ is the diagonal matrix that is formed from the diagonal elements of $Q_{t}$ which is a positive definite matrix which follows the follows the asymmetric dynamic conditional correlation structure

$$
Q_{t}=\Omega+\theta_{1} u_{t-1} u_{t-1}^{\prime}+\theta_{2} Q_{t-1}+g \eta_{t-1} \eta_{-1}^{\prime}
$$

where $\eta_{t}=\min \left[u_{t}, 0\right]$, the product of $\eta_{i, t} \eta_{j, t}$ is nonzero if and only if both shocks are negative (for detail see e.g. Cappiello et al., 2006); Alexander, 2008; Engle, 2009).

Table 4 reports the results for the ADCC-GARCH model of both step1 and step 2. In step 1, an asymmetric univariate GARCH model is fitted for each of volatility index residuals series (residuals received from VAR (2) specification). Results are reported in Panel A, as be seen the coefficient, $\beta_{i}$, the GARCH coefficient is highly significant for all three volatility indices. It implies that shock to each volatility index is highly persistent, particularly the emerging markets volatility followed by the US volatility and the least persistent is the developed markets volatility. However, the shock to variance, $\alpha_{i}$, the ARCH coefficient is also found to be significant for each volatility index but the ARCH effect is high in magnitude for the VIX and followed by VXEFA and the least is found in the VXEEM. Finally, if we look into, $\gamma_{i}$, the asymmetric effect of negative and positive shocks of volatility on the volatility of each market, the VIX and VXEEM present asymmetric volatility; however, the asymmetry in volatility is found insignificant for the VXEFA. The sighs of the asymmetric effects are negative and consistent with the intuition that negative shocks to volatility indices decreases future volatilities which should be opposite in the case of return shocks. 
In panel B of Table 4 reports the results for step 2, the ADCC results. The first row shows the average dynamic conditional correlations between the volatility indices over the sample period from March 16, 2011 to October 30, 2015. It is found that on average these volatility indices are highly correlated, correlation of 0.76 between the US and emerging market volatilities, followed by the US and developed market 0.73 , and the least between developed markets and emerging markets about 0.71 . The persistence in correlation between the pair is captured by $\theta_{2}$. As can be seen, the correlation between VIX and VXEFA is highly persistent followed between the VIX and VXEEM. The asymmetry in correlation between the pair is captured by $g$, as can be observed all pairs show asymmetry in correlations. Implies that simultaneous decline in volatilities between the pair and simultaneous spikes in volatilities have asymmetric impact on correlations.

Figure 4 shows the pairwise dynamic conditional correlations (DCCs) received from ADCC-GARCH model from March 16, 2011 to October 30, 2015. Panel A depicts the DCCs between the VIX and VXEFA. As can be seen the DCCs vary considerably during the sample period; therefore, we can easily reject the assumption of constant correlations. The variation in correlations is in the range from 0.15 (lowest) to 0.95 (highest). The highest correlation between the two indices is seen during the second of half of 2011, can be attributed to the European debt crises. Whereas the lowest level of correlation is found in early part of 2013 which is a more tranquil period.

Panel B of Figure 4 shows the evolution of DCCs between the VIX and VXEEM. Here also we can observe variation in DCCs though in a smaller range from 0.44 (lowest) to 0.93 (highest). The highest correlation between VIX and VXEEM is found during the European debt crises (third quarter of 2011).

Finally, the DCCs between VXEFA and VXEEM is depicted in Panel C of Figure 4. The variations in DCCs are considerable as it varies between 0.14 (lowest) and 0.95 (highest). 
The highest correlation between the two indices is found during the recent Chines stock market crises (second quarter of 2015).

In summary, the ADCC-GARCH results provides some important findings: First, we assert that there is noticeable evidence that the fear index has higher time-varying linkages in second moments of volatilities with the developed and emerging markets over the sample period. In particular, the fear index and emerging markets are highly correlated and the dynamic correlation is more of persistent in nature. However, the DCCs between the developed markets and emerging markets vary over time and not that persistent. Second, the dynamic correlations among the markets increases during the crises periods, for example, as we can observe high degree of correlations during the third quarter of 2011, when the euro zone sovereign debt crisis erupts, and during the Chines stock market crises (third quarter of 2015); however, in the tranquil periods the DCCs among the markets decrease, that can be noticed in 2013.

\section{Conclusions}

In this paper, we investigate the cross-market volatility dependencies and spillover effects in both first and second moments of volatilities for the US, developed, and emerging stock markets. We use CBOE volatility indices as proxies for their respective markets for instance, the VIX index (for the US stock market), the VXEFA (for developed markets), and the VXEEM (for emerging market). We find significant cross-market dependencies in first as well as well as in second moments of volatilities. The fear index leads the emerging and developed market volatilities thus has information content for volatilities of both markets. An unexpected shock to the fear index spillovers contemporaneously to the developed and emerging markets and explain $57.07 \%$ and $63.77 \%$ their volatility shocks, respectively; while the effect of the volatility shock stays for about 7 days. Moreover, we find interdependencies in second 
moments of volatilities among studied markets. The correlations of the three markets are timevarying not static. The degree of time-varying corrosions of the fear index with the other two market is high comparatively. And the fear index drives the time-varying correlations with the emerging markets with highly persistent manner. The dynamic correlations increase in crises period decreases in the tranquil periods.

These significant cross-market volatility linkages in both moments of volatilities. Particularly, a dominant role of the US volatility and its unexpected shock spillover to the emerging stock markets would reduce the benefits of diversification for the international investors in the emerging markets. However, strategies can be devised to hedge the risks arising from the equity positions in the emerging markets by taking long positions in the call options on the emerging market volatility index (the VXEEM) or buying futures on the VXEEM. Such strategy would offset the losses on the equity positions in the emerging markets.

\section{Notes}

1. Particularly institutional investors who actively seek to invest in high yield emerging market equities and diversify their portfolios across borders to receive the benefits of diversification (i.e. reducing risks).

2. The VIX index is widely dubbed as the investors "fear index" (see Whaley 2000, 2009).

3. www.cboe.com/vix

4. www.cboe.com/vxefa

5. www.cboe.com/vxeem

\section{References}

Äijö, J. 2008. "Implied Volatility Term Structure Linkages between VDAX, VSMI and VSTOXX Volatility Indices." Global Finance Journal 18, no.3: 290-302. Alexander, C. 2008. "Market Risk Analysis: Practical Financial Econometrics." Wiley; Volume II edition. 
Bekaert, G., and C. Harvey. 2014. "Emerging Equity Markets in a Globalizing World." Columbia Business School Working Paper, New York.

Bekaert, G.; C. Harvey.; C. Lundblad.; and S. Siegel. 2011. "What Segments Equity Markets? Review of Financial Studies 24, no.12:3841-3890.

Blair, B.; S. Poon.; S. Taylor. 2001. " Forecasting S\&P 100 Volatility: The Incremental Information Content of Implied Volatilities and High-frequency Index Returns." Journal of Econometrics 105, no.1:5-26.

Bollerslev, T.; G. Tauchen.; and H. Zhou. 2009. " Expected Stock Returns and Variance Risk Premia." Review of Financial Studies 22, no.11:4463-4492.

Cappiello, L.; R. Engle.; and K. Sheppard. 2006. " Asymmetric Dynamics in the Correlations of Global Equity and Bond Returns.” Journal of Financial Econometrics 4, no.4:537 -572 .

Diebold, F., and K.Yilmaz. 2009. "Measuring Financial Asset Return and Volatility Spillovers, with Application to Global Equity Markets.” The Economic Journal 119, no. 534:158 171.

Engle, R. 2002. "Dynamic Conditional Correlation a Simple Class of Multivariate GARCH Models." Journal of Business and Economic Statistics 20, no.3:339-350.

Engle, R. 2009. "Anticipating Correlations." Princeton University Press.

Granger, J. 1969. "Investigating Causal Relations by Econometric Models and Cross-spectral Methods." Econometrica 37, no.3: 424-438.

Kenourgios, D. 2014. "On Financial Contagion and Implied Market Volatility." International Review of Financial Analysis 34, 21-30.

Mills, T., and R. Markellos. 2008. "The Econometric Modelling of Financial Time Series." Cambridge University Press; 3rd edition.

Nikkinen, J., and P. Sahlström. 2004. "International Transmission of Uncertainty Implicit in Stock Index Option Prices." Global Finance Journal 15,no.1: 1-15.

Nikkinen, J.; P. Sahlström.; and S. Vähämaa. 2006. "Implied Volatility Linkages among Major European Currencies." Journal of International Financial Markets, Institutions, and Money 16, no.2: 87-103.

Peng, W., and W, Ng. 2012. "Analysing Financial Contagion and Asymmetric Market Dependence with Volatility Indices via Copulas." Annals of Finance 8, no.1:49-74.

Persaran, M., and Y. Shin. 1998. "Generalized Impulse Response Analysis in Linear Multivariate Models." Economics Letters 58, no.1: 17-29.

Rizova, S. 2013. "Trade Momentum." Journal of International Financial Markets, Institutions, and Money 24, 258-293.

Skiadopoulos, G. 2004. "The Greek Implied Volatility Index: Construction and Properties." Applied Financial Economics 14, no.16 : 1187-1196.

Whaley, R. 2000. “The Investor Fear Gauge.” Journal of Portfolio Management 26, no.3:1217. , 2009. "Understanding the VIX.” Journal of Portfolio Management 35, no.3:98-105. 


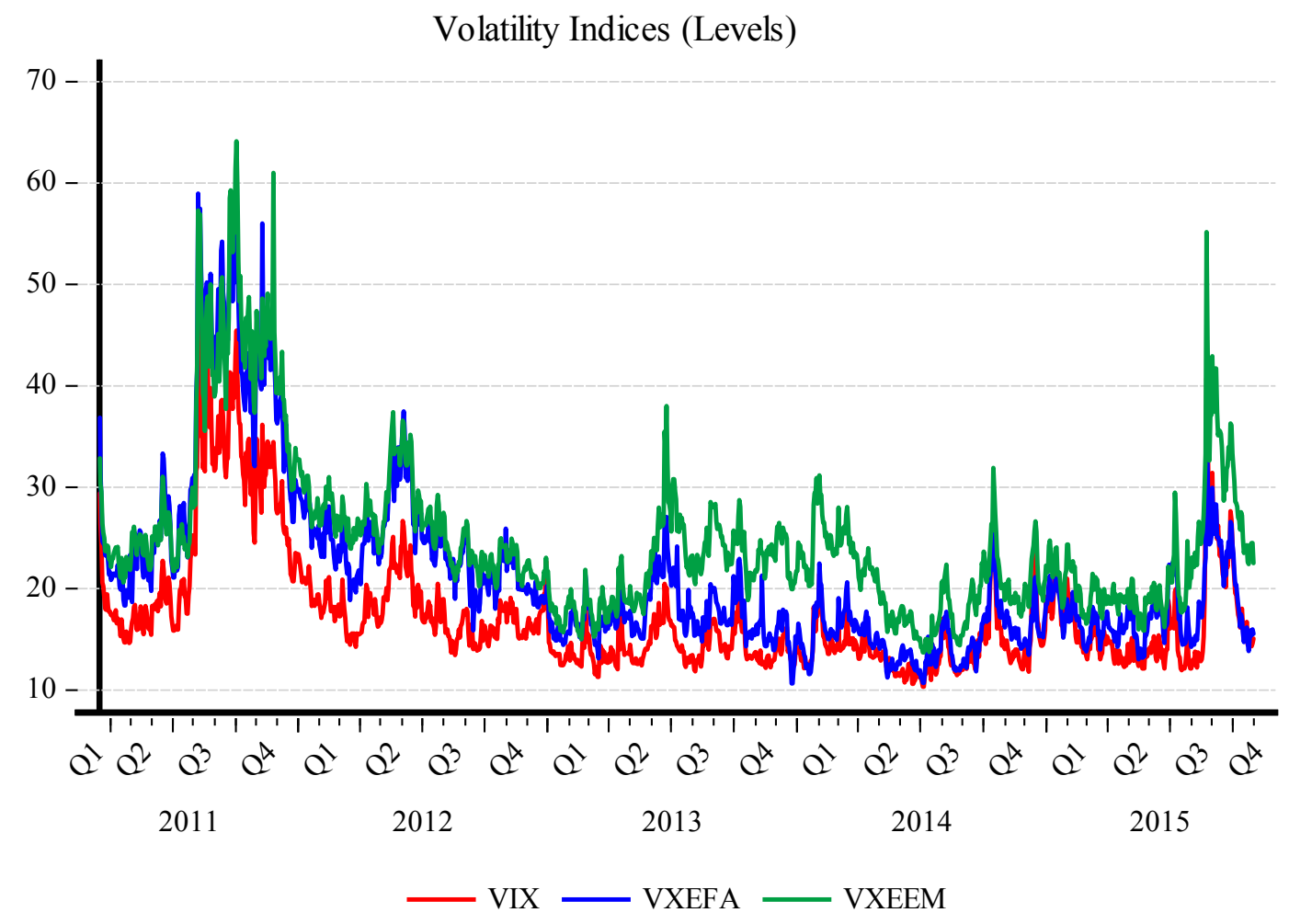

Figure 1. Figure 1 shows a time series plot of the VIX, VXEFA, and VXEEM over the sample period March 16, 2011 to October 30, 2015. 
Table 1

Descriptive statistics for volatility indices

\begin{tabular}{lllllll}
\hline \multicolumn{4}{l}{ Volatility Levels } & \multicolumn{4}{l}{ Volatility Log Changes } \\
\hline & VIX & VXEFA & VXEEM & $\Delta$ VIX & $\Delta$ VXEFA & $\Delta$ VXEEM \\
\hline Mean & 17.3755 & 21.2963 & 24.8524 & -0.0006 & -0.0007 & -0.0003 \\
Median & 15.5700 & 18.6050 & 23.2000 & -0.0024 & -0.0027 & -0.0023 \\
Maximum & 48.0000 & 58.9600 & 64.1000 & 0.4055 & 0.4548 & 0.5049 \\
Minimum & 10.3200 & 10.6500 & 13.7100 & -0.3141 & -0.2936 & -0.2981 \\
Std. Dev. & 5.9792 & 8.3751 & 7.8554 & 0.0735 & 0.0720 & 0.0620 \\
Skewness & 2.0787 & 1.8501 & 1.8150 & 0.7936 & 0.6288 & 0.9879 \\
Kurtosis & 7.5550 & 6.5965 & 6.9476 & 6.6300 & 6.0245 & 8.8076 \\
Jarque-Bera & 1914.30 & 1340.19 & 1447.58 & 790.05 & 540.04 & 1894.16 \\
Prob. & 0.0000 & 0.0000 & 0.0000 & 0.0000 & 0.0000 & 0.0000 \\
$\rho_{1}$ & $0.962^{* * *}$ & $0.973^{* * *}$ & $0.967^{* * *}$ & $-0.070^{* *}$ & $-0.078^{* * *}$ & -0.026 \\
$\rho_{2}$ & $0.933^{* * *}$ & $0.953^{* * *}$ & $0.940^{* * *}$ & $-0.000^{*}$ & $-0.065^{* * *}$ & -0.003 \\
ADF & $-3.80^{* * *}$ & $-3.56^{* * *}$ & $-3.00^{* *}$ & $-37.21 * * *$ & $-37.51^{* * *}$ & $-22.75^{* * *}$ \\
No. Obs & 1208 & 1208 & 1208 & 1208 & 1208 & 1208 \\
\hline
\end{tabular}

Table reports the descriptive statistics for the three implied volatility indices. Descriptive statistics for volatility levels are reported in first three columns of the table. While log volatility changes are reported in last three columns. ADF is the t-statistics for the Augmented Dicky-Fuller (an intercept is included in the test equation).

$* * *, * *$ and $*$ denote rejection of the null hypothesis at the $1 \%, 5 \%$ and $10 \%$ significance levels, respectively. 


\section{Table 2}

Vector Autoregression (2) estimates

\begin{tabular}{llll}
\hline & $\Delta \mathrm{VIX}$ & $\Delta \mathrm{VXEFA}$ & $\Delta$ VXEEM \\
\hline Intercept & -0.00053 & -0.00077 & -0.00019 \\
& {$[-0.252]$} & {$[-0.379]$} & {$[-0.105]$} \\
$\Delta \mathrm{VIX}_{\mathrm{t}-1}$ & $-0.11260^{* *}$ & $0.17548^{* * *}$ & $0.15630^{* * *}$ \\
& {$[-2.101]$} & {$[3.425]$} & {$[3.468]$} \\
$\Delta \mathrm{VIX}_{\mathrm{t}-2}$ & 0.03125 & $0.14156^{* * *}$ & $0.12695^{* * *}$ \\
& {$[0.582]$} & {$[2.758]$} & {$[2.811]$} \\
$\Delta \mathrm{VXEFA}_{\mathrm{t}-1}$ & -0.00313 & $-0.34588^{* * *}$ & -0.01138 \\
& {$[-0.063]$} & {$[-7.319]$} & {$[-0.274]$} \\
$\Delta \mathrm{VXEFA}_{\mathrm{t}-2}$ & -0.04589 & $-0.26593^{* * *}$ & $-0.05460^{*}$ \\
& {$[-0.932]$} & {$[-5.652]$} & {$[-1.319]$} \\
$\Delta \mathrm{VXEEM}_{\mathrm{t}-1}$ & 0.06769 & $0.16761^{* * *}$ & $-0.16928^{* * *}$ \\
& {$[1.110]$} & {$[2.875]$} & {$[-3.301]$} \\
$\Delta \mathrm{VXEEM}_{\mathrm{t}-2}$ & -0.01144 & $0.11350^{* *}$ & $-0.07346^{*}$ \\
& {$[-0.188]$} & {$[1.954]$} & {$[-1.438]$} \\
$\mathrm{R}^{2}$ & $0.73 \%$ & $5.47 \%$ & $1.57 \%$ \\
\hline
\end{tabular}

$* * *, * *$ and $*$ denote rejection of the null hypothesis at the $1 \%, 5 \%$ and $10 \%$ significance levels respectively. 


\section{Table 3}

Granger causality tests for implied volatility indices

\begin{tabular}{lll}
\hline Null Hypothesis & \multicolumn{2}{l}{ 2 Lags } \\
\cline { 2 - 3 } & F-Statistics & P-Value \\
\hline$\Delta$ VXEFA does not Granger Cause $\Delta$ VIX & 0.7123 & 0.490 \\
$\Delta$ VIX does not Granger Cause $\Delta$ VXEFA & $22.4357^{* * * *}$ & 0.000 \\
$\Delta$ VXEEM does not Granger Cause $\Delta$ VIX & 0.9714 & 0.379 \\
$\Delta$ VIX does not Granger Cause $\Delta$ VXEEM & $8.2499^{* * * *}$ & 0.000 \\
$\Delta$ VXEEM does not Granger Cause $\Delta$ VXEFA & $19.6223^{* * *}$ & 0.000 \\
$\Delta$ VXEFA does not Granger Cause $\triangle$ VXEEM & 1.0747 & 0.342 \\
\hline
\end{tabular}

$* * *, * *$ and $*$ Denote rejection of the null hypothesis at the $1 \%, 5 \%$, and $10 \%$ significance levels respectively. 
Panel A

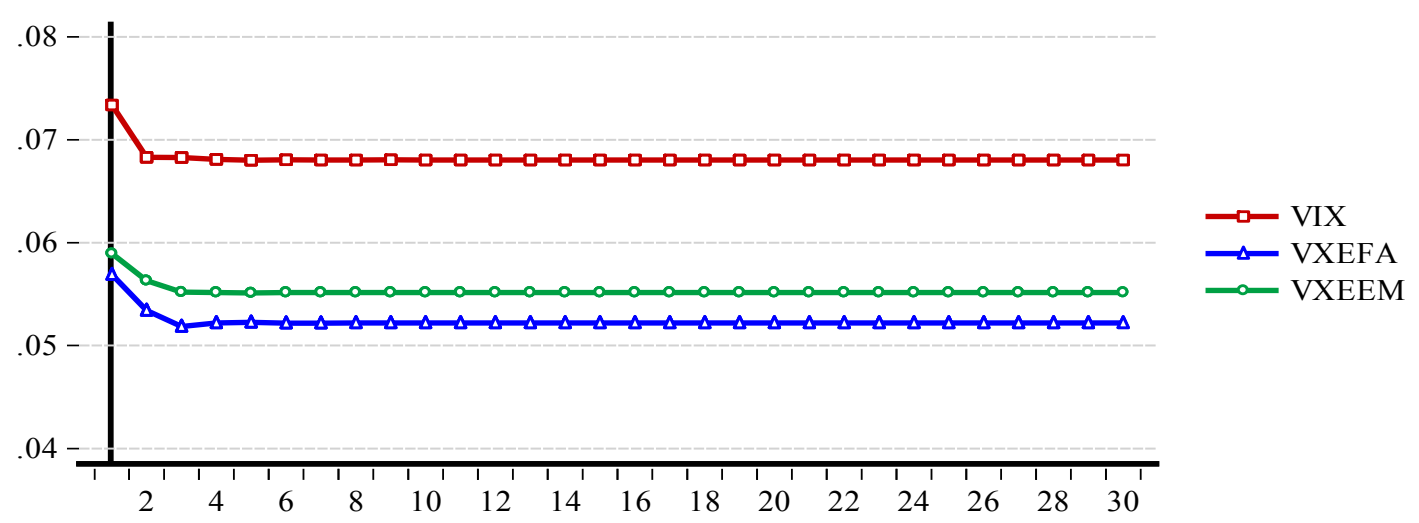

Panel B

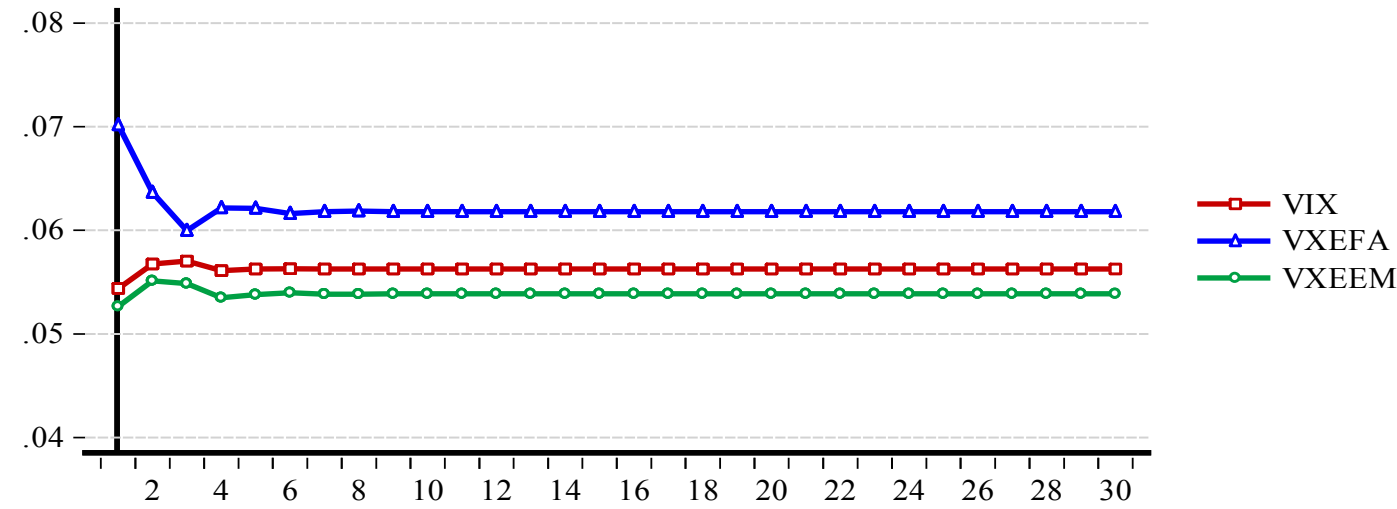

Panel C

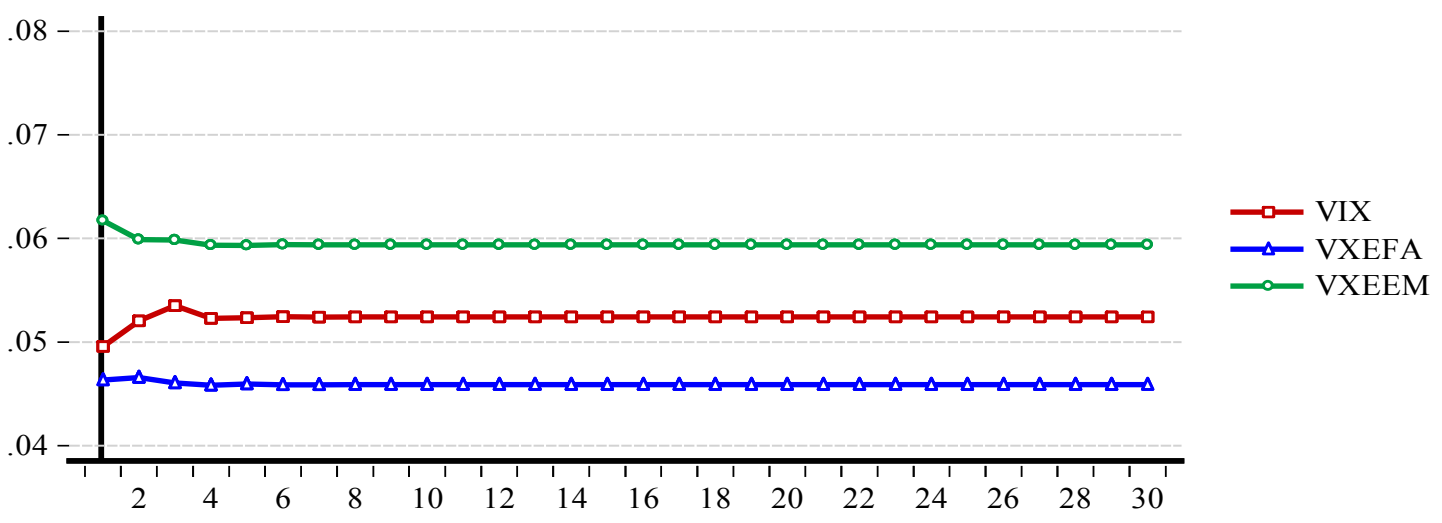

Figure 2.

This figure shows the accumulated generalized impulse response functions for the three volatility indices. Panels A, B and C depict responses of the VIX, VXEFA, and VXEEM to a unit shock in each volatility index, respectively. Red line represent the impulse response function of each volatility index to a unit shock in the VIX, blue line with a unit shock in the VXEFA, and green line with a unit shock in the VXEEM, respectively. 
Panel A: Variance Decomposition of VIX

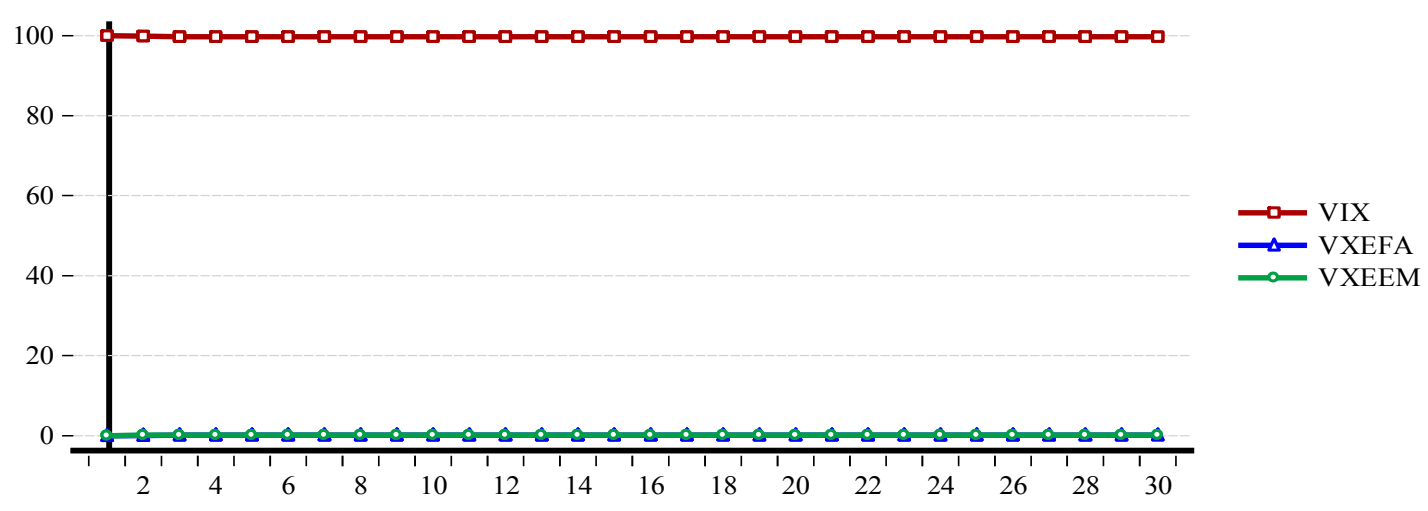

Panel B: Variance Decomposition of VXEFA

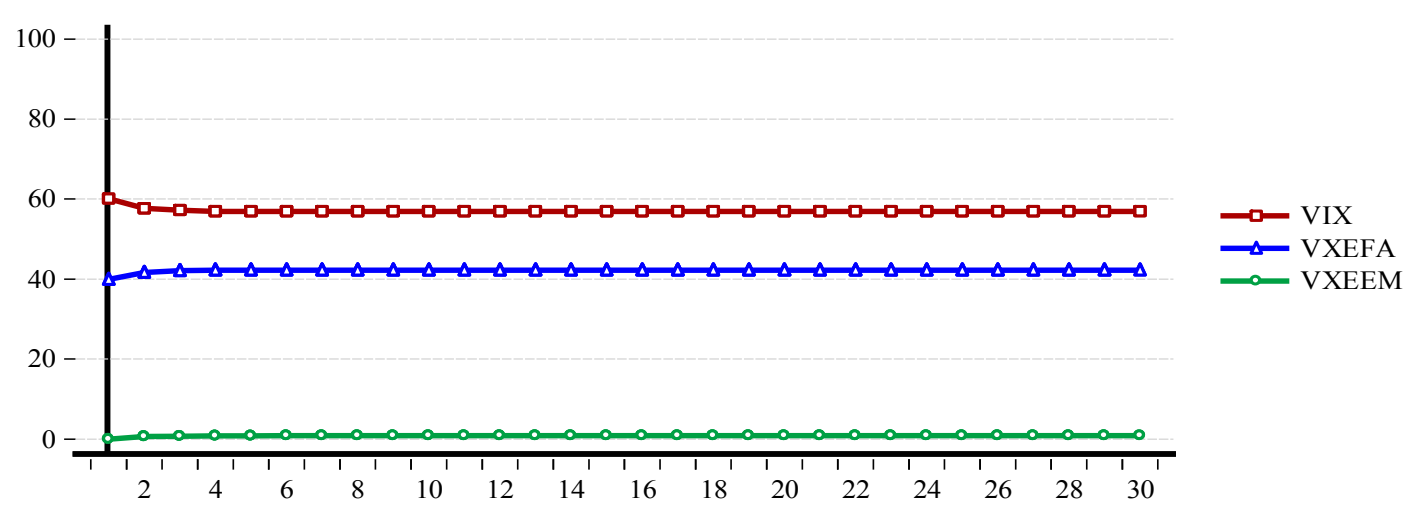

Panel C: Variance Decomposition of VXEEM

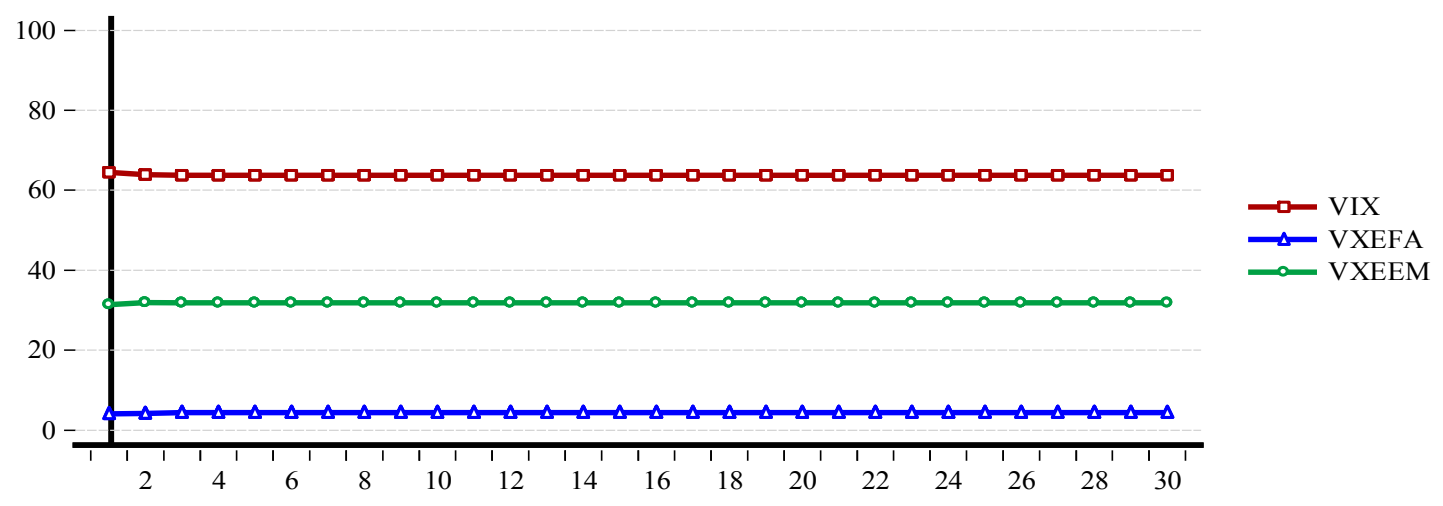

Figure 3. This figure shows variance decomposition of log changes in volatility indices. Panel $\mathrm{A}, \mathrm{B}$ and $\mathrm{C}$ reports variance decompositions of log changes in VIX, VXEFA, and VXEEM, respectively. For each volatility index, red line represent contributions from the VIX, blue line from the VXEFA, and green line from the VXEEM, respectively. 
Table 4. DCC Model results for both step 1 and 2

Panel A: DCC Models results with univariate GARCH fitted in step 1.

\begin{tabular}{llll}
\hline & $\Delta$ VIX & $\Delta$ VXEFA & $\Delta$ VXEEM \\
\hline$\omega_{i}$ & $0.00045^{* * *}$ & $0.00118^{* * *}$ & $0.00016^{* * *}$ \\
& {$[3.981]$} & {$[2.910]$} & {$[3.380]$} \\
$\alpha_{i}$ & $0.19848^{* * *}$ & $0.17060^{* * *}$ & $0.07265^{* * *}$ \\
& {$[4.868]$} & {$[2.947]$} & {$[3.976]$} \\
$\beta_{i}$ & $0.83649^{* * *}$ & $0.64215^{* * *}$ & $0.93647^{* * *}$ \\
& {$[26.536]$} & {$[6.455]$} & {$[46.889]$} \\
$\gamma_{i}$ & $-0.27914^{* * *}$ & -0.09319 & $-0.13544^{* * *}$ \\
& {$[-5.703]$} & {$[-1.387]$} & {$[-4.677]$} \\
\hline
\end{tabular}

Panel B: ADCC model Results Step 2

\begin{tabular}{llll}
\hline & $\Delta$ VIX- $\Delta$ VXEFA & $\Delta$ VIX- $\Delta$ VXEEM & $\Delta$ VXEFA- $\Delta$ VXEEM \\
\hline Cor $_{i j}$ & 0.73154 & 0.76048 & 0.71376 \\
\hline$\theta_{1}$ & $0.08469^{* * *}$ & $0.08017^{* * *}$ & $0.10132^{* * *}$ \\
\hline & {$[4.380]$} & {$[3.247]$} & {$[3.999]$} \\
\hline$\theta_{2}$ & $0.86627^{* * *}$ & $0.78312^{* * *}$ & $0.76693^{* * *}$ \\
\hline$g$ & {$[25.025]$} & {$[8.803]$} & {$[11.173]$} \\
\hline & $-0.01878^{* *}$ & $-0.03347^{* *}$ & $-0.03783^{* * *}$ \\
\hline$* * * * *$ & {$[-2.256]$} & {$[-2.643]$} \\
\hline
\end{tabular}


Panel A: ADCC between VIX and VXEFA

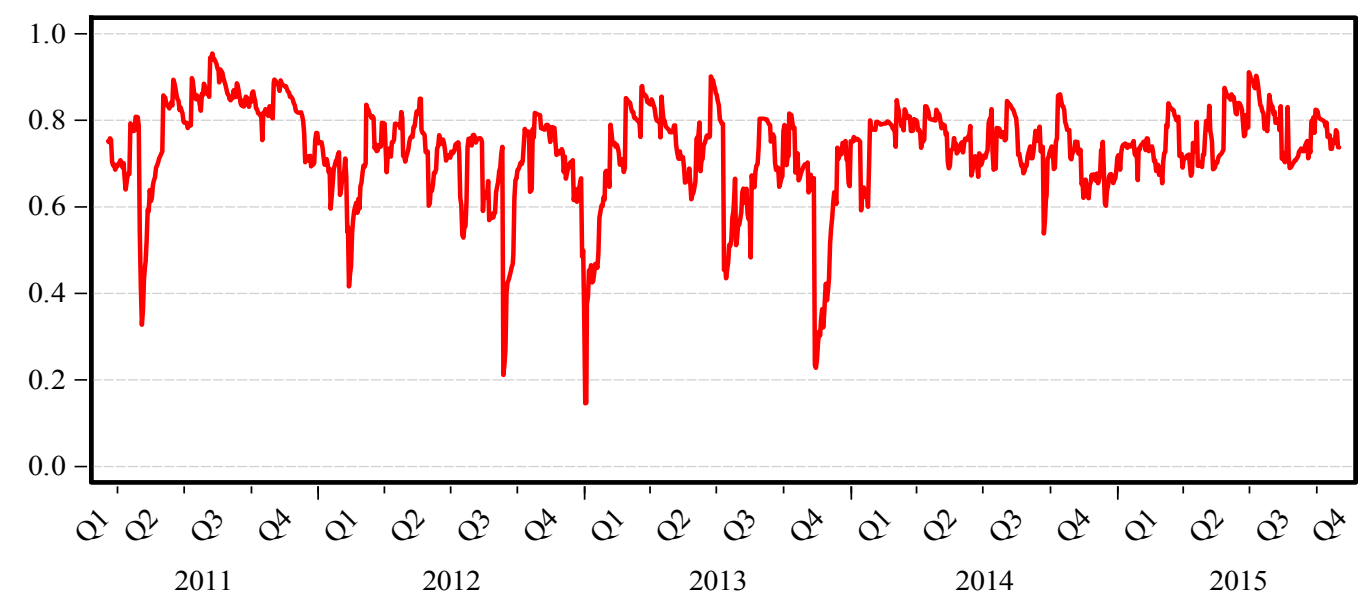

Panel B: ADCC between VIX and VXEEM

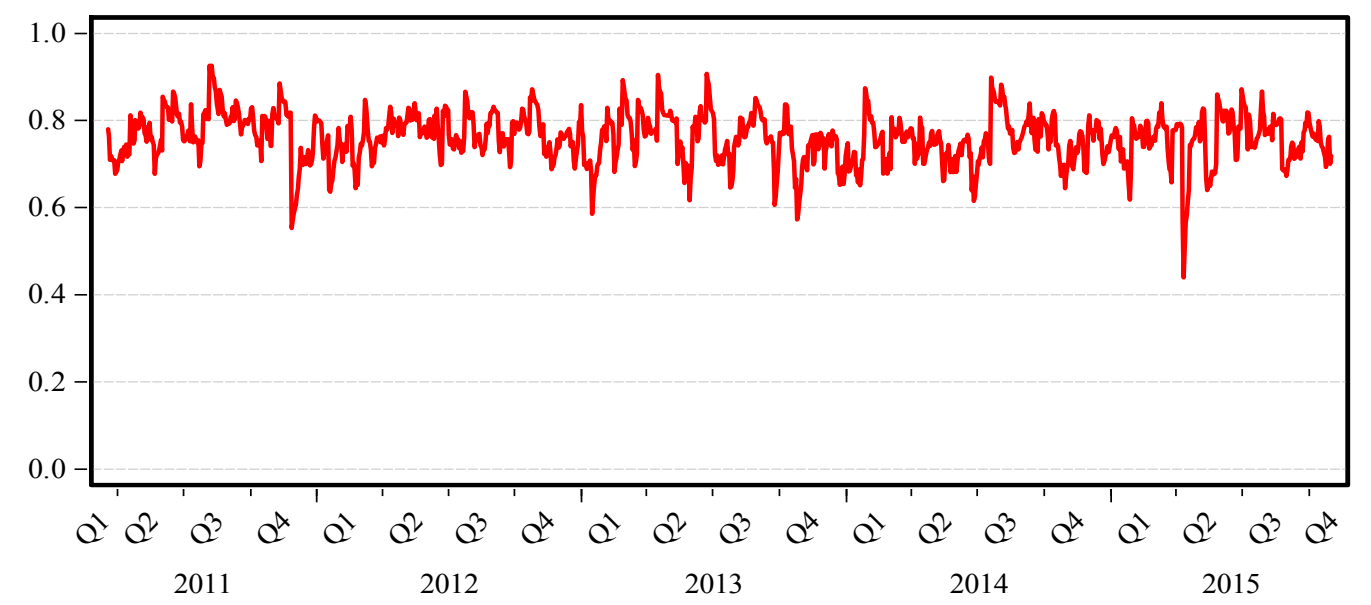

Panel C: ADCC between VXEFA and VXEEEM

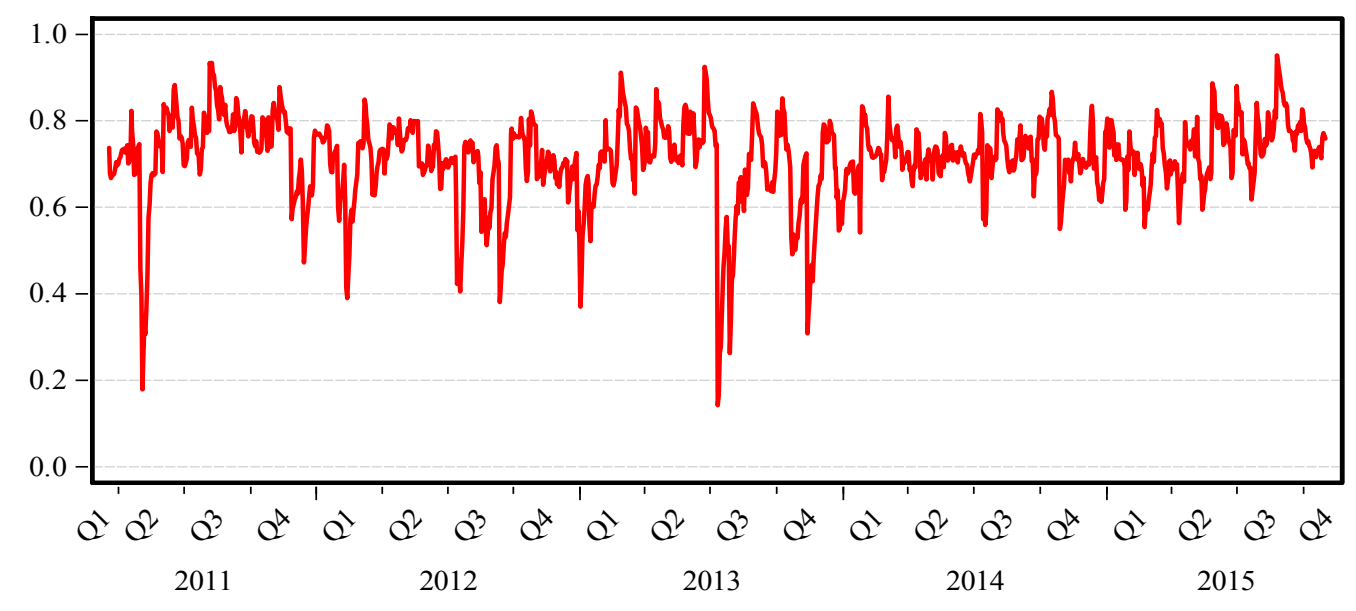

Figure 4. This figure shows the dynamic conditional correlations among the three volatility indices. Panel A shows dynamic conditional correlations between VIX and VXEFA, panel B between VIX and VXEEM, and Panel $\mathrm{C}$ between VXEFA and VXEEM indices from March 16, 2011 to October 3, 2015. 